\title{
Cerebral localization of chronic myelomonocytic leukemia: a case report
}

\author{
Clémence Haméon ${ }^{1 *} \mathbb{D}$, Cécilia Rousselot ${ }^{2}$, Flavie Arbion², Justine Cibron', Jean-Philippe Cottier ${ }^{3}$, \\ Christophe Destrieux ${ }^{4}$, Olivier Hérault ${ }^{5}$ and Emmanuel Gyan ${ }^{1}$
}

\begin{abstract}
Background: Chronic myelomonocytic leukemia is a myelodysplastic/myeloproliferative neoplasm characterized by the infiltration of blood and bone marrow by immature monocytes. Cerebral localization of chronic myelomonocytic leukemia has never been described.

Case presentation: We report the case of a Caucasian 59 year-old man with multiorgan chronic myelomonocytic leukemia infiltration, associated with uncommon brain involvement. There was no evidence of evolution to acute myeloid leukemia. The evidence of cerebral infiltration by chronic myelomonocytic leukemia was made after autopsy.

Conclusions: The fatal outcome of the patient raises the question of the potential benefit of early specific treatment, such as demethylating agents or intensive chemotherapy. Sharing such images of atypical and rapidly evolving chronic myelomonocytic leukemia and the disease history may help clinical decision-making in the future.
\end{abstract}

Keywords: Chronic myelomonocytic leukemia, Cerebral localization, Case report

\section{Introduction}

Chronic myelomonocytic leukemia (CMML) is a malignant neoplasm that exhibits both myelodysplastic and myeloproliferative features and is characterized by peripheral monocytosis. The clinical presentation is nonspecific, with general symptoms, such as asthenia, night sweats, and weight loss, in symptomatic patients. Neurological manifestations are rare [1].

Molecular biology can detect numerous mutations, such as ASXL1, TET2, and SRSF2. The mutation of SETBP1 is found in $15 \%$ of CMML cases [2, 3].

We report the case of a Caucasian 59-year-old man with multiorgan CMML infiltration, including uncommon brain involvement.
*Correspondence: clemencehameon@gmail.com

${ }^{1}$ Department of Hematology, Tours Hospital, Tours, France

Full list of author information is available at the end of the article

\section{Case presentation}

A Caucasian 59-year-old man with a history of hypothyroidy and fatty liver was diagnosed in 2018 with a myelodysplastic syndrome with multilineage dysplasia (MDS-MLD) [4] and a very low risk by the R-IPSS at our facility. There was no family medical history. The patient was married, had two children, and worked as a social worker. He did not consume alcohol nor tobacco. The only treatment was L-thyroxine $50 \mu \mathrm{g} / \mathrm{day}$.

Laboratory tests showed a leukocyte count of $3.9 \times 10^{9} \mathrm{~L}$, with neutrophils at $1.5 \times 10^{9} / \mathrm{L}$ and monocytes at $1.49 \times 10^{9} / \mathrm{L}$, a platelet count of $113 \times 10^{9} / \mathrm{L}$, and hemoglobin at $115 \mathrm{~g} / \mathrm{L}$. The bone-marrow blast count was $1.4 \%$, and cytogenetics were normal, with no Philadelphia chromosome. Next-generation sequencing (NGS) detected a SETBP1 mutation, with a variant allelic fraction (VAF) of $0.21 \%$. Biological and clinical monitoring was decided.

In December 2019, a brutal deterioration of the general state, with a loss of $13 \mathrm{~kg}$, night sweats, major fatigue, and loss of appetite, raised doubts about the diagnosis. original author(s) and the source, provide a link to the Creative Commons licence, and indicate if changes were made. The images or other third party material in this article are included in the article's Creative Commons licence, unless indicated otherwise in a credit line to the material. If material is not included in the article's Creative Commons licence and your intended use is not permitted by statutory regulation or exceeds the permitted use, you will need to obtain permission directly from the copyright holder. To view a copy of this licence, visit http://creativecommons.org/licenses/by/4.0/. The Creative Commons Public Domain Dedication waiver (http://creativeco mmons.org/publicdomain/zero/1.0/) applies to the data made available in this article, unless otherwise stated in a credit line to the data. 
The patient's body temperature was $36.7^{\circ} \mathrm{C}$, heart rate 95 beats per minute, blood pressure 103/64 mmHg, and oxygen saturation at $100 \%$ on ambient air. Cardiopulmonary auscultation was normal. He was conscious, oriented, and had a Glasgow score of 15, without detectable abnormalities on neurological clinical examination. His weight was $60.5 \mathrm{~kg}$. Laboratory tests showed a leukocyte count of $29.7 \times 10^{9} / \mathrm{L}$, with neutrophils at $23.46 \times 10^{9} / \mathrm{L}$ and monocytes at $1.78 \times 10^{9} / \mathrm{L}$, a platelet count of $83 \times 10^{9} / \mathrm{L}$, and hemoglobin at $78 \mathrm{~g} / \mathrm{L}$. Another medullary aspiration was performed and showed major dysplasia without excess blasts and a cytological aspect of CMML-0. Immunophenotyping showed a near-absence of type MO3 monocytes, consistent with a diagnosis of CMML. A PET scan was performed and detected several deep lymphadenopathies with moderate hypermetabolism [maximum standardized uptake value (SUV) 3.6]. They had a maximum size of $12 \mathrm{~mm}$ and were not puncturable. There was no evidence of another cancer. Treatment with hydroxyurea (three tablets per day) was introduced for the hyperleukocytosis and was administered over 3 weeks.

In January 2020, the appearance of psychomotor slowdown led to admission to the hematology department of Tours Hospital. Subsequently, the patient's condition quickly worsened with the occurrence of severe problems of alertness and aphasia. At this time, clinical examination showed a Glasgow score of 11 (M6V2E3), with bilateral nonreactive myosis and right central facial paralysis. There was no motor or sensory deficit of the limbs within the limits of clinical examination in such a state of consciousness.

Laboratory tests showed a hemoglobin level of $77 \mathrm{~g} / \mathrm{L}$, a platelet count of $36 \times 10^{9} / \mathrm{L}$, and a leukocyte count of $37 \times 10^{9} / \mathrm{L}$, with neutrophils at $31 \times 10^{9} / \mathrm{L}$ and monocytes at $3 \times 10^{9} / \mathrm{L}$ (Table 1 ). Infectious assessment was negative, with sterile hemocultures in bacteriology and mycology and negative serologies for Cryptococcus, Toxoplasma, HIV, HBV, HBC, CMV, EBV, and syphilis. Beta-D-glucan assessment was negative. Autoimmune assessment, including for ANA, was also negative. Cerebral CT showed multiple hemorrhagic nodular lesions (Fig. 1A). On MRI (Fig. 1B-C) these CNS lesions were heterogeneous, without enhancement after gadolinium administration. The MRI also showed multiple supraand infratentorial hemorrhagic lesions of varying age, in favor of leukemic infiltration as well as the beginning of left temporal engagement (Fig. 1B-D). We could not perform a lumbar puncture because of the risk of engagement. Treatment with high-dose corticosteroids, consisting of $100 \mathrm{mg}$ intravenous methylprednisolone per day, was introduced, and the patient was transferred to intensive care because of his worsening state of consciousness.
Table 1 Results of laboratory findings on 13 January 2020

\begin{tabular}{|c|c|}
\hline \multicolumn{2}{|l|}{ Blood counts } \\
\hline Hemoglobin & $77 \mathrm{~g} / \mathrm{L}$ \\
\hline Platelets & $36 \times 10^{9} / \mathrm{L}$ \\
\hline Leukocytes & $37 \times 10^{9} / \mathrm{L}$ \\
\hline Neutrophils & $31 \times 10^{9} / \mathrm{L}$ \\
\hline Monocytes & $3 \times 10^{9} / \mathrm{L}$ \\
\hline \multicolumn{2}{|l|}{ Biochemistry } \\
\hline Sodium & $142 \mathrm{mmol} / \mathrm{L}$ \\
\hline Potassium & $4.3 \mathrm{mmol} / \mathrm{L}$ \\
\hline Calcium & $2.33 \mathrm{mmol} / \mathrm{L}$ \\
\hline Albumin & $47 \mathrm{~g} / \mathrm{L}$ \\
\hline Phosphates & $1.79 \mathrm{mmol} / \mathrm{L}$ \\
\hline Creatinine & $97 \mu \mathrm{mol} / \mathrm{L}$ \\
\hline Glomerular filtration rate (MDRD) & $73 \mathrm{~mL} / \mathrm{min} / 1.73 \mathrm{~m}^{2}$ \\
\hline Uric acid & $458 \mu \mathrm{mol} / \mathrm{L}$ \\
\hline Total bilirubin & $10 \mu \mathrm{mol} / \mathrm{L}$ \\
\hline ASAT & $41 \mathrm{UI} / \mathrm{L}$ \\
\hline ALAT & $25 \mathrm{UI} / \mathrm{L}$ \\
\hline Alkaline phosphatase & 94 UI/L \\
\hline Gamma-GT & $60 \mathrm{UI} / \mathrm{L}$ \\
\hline Lactate dehydrogenase & 1039 UI/L \\
\hline \multicolumn{2}{|l|}{ Microbiology } \\
\hline Hemocultures & Negative \\
\hline Bacterial & Negative \\
\hline Fungal & Negative \\
\hline Urinary analysis & Negative \\
\hline Beta-D-glucan & Negative \\
\hline \multicolumn{2}{|l|}{ Serologies } \\
\hline Cryptococcus & Negative \\
\hline Toxoplasma & Negative \\
\hline HIV & Negative \\
\hline HBV & Negative \\
\hline $\mathrm{HBC}$ & Negative \\
\hline CMV & Negative \\
\hline EBV & Negative \\
\hline Syphilis & Negative \\
\hline
\end{tabular}

MDRD, modification of diet in renal disease; ASAT, aspartate aminotransferase; ALAT, alanine aminotransferase; HIV, human immunodeficiency viruses; HBV, hepatitis B virus; $\mathrm{HBC}$, hepatitis C virus; CMV, cytomegalovirus; EBV, Epstein-Barr virus

A neurosurgical diagnosis could not be performed owing to the nontissular hemorrhagic description of the lesions by imaging. The patient died on 15 January 2020.

An autopsy was performed. Macroscopic sections of the brain showed multiple hemorrhagic lesions (Fig. 2A). Microscopic analyses showed infiltration by relatively immature myeloid elements and hemorrhagic phenomena (Fig. 2B). Immunohistochemistry analyses of the brain tissue showed positivity of the lesion for antibodies against CD15 (Fig. 2C) and MPO (Fig. 2D). No 

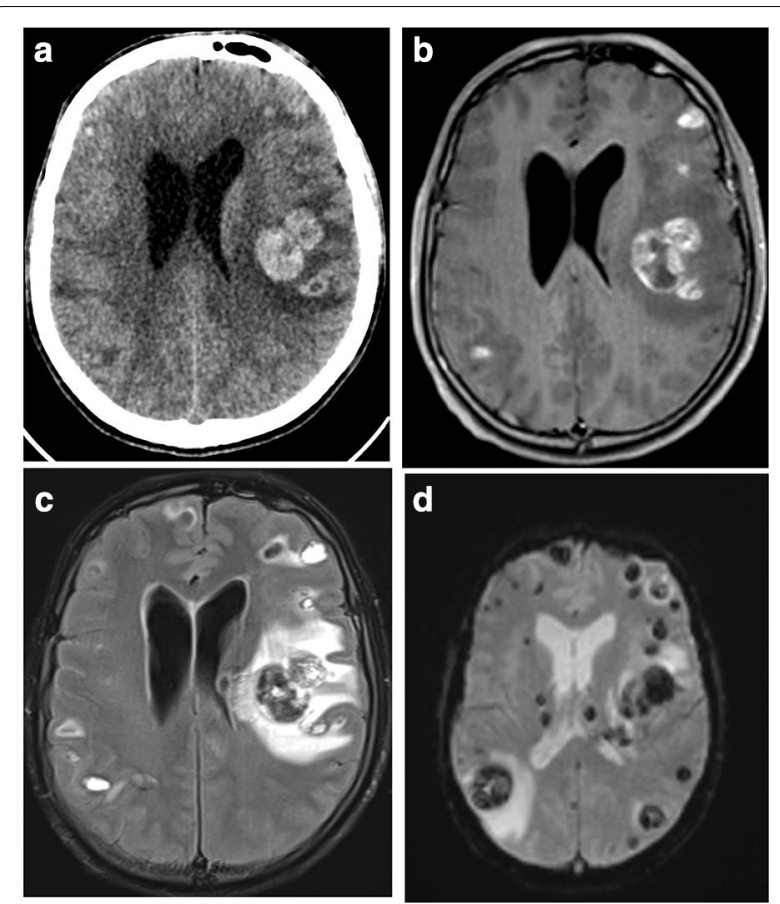

Fig. 1 Axial nonenhanced computed tomography (NECT) (A) showing multiple hyperdense lesions. The hemorrhagic lesions were very heterogeneous on T1- (B), T2-FLAIR (C), and perfusion (D)-weighted MRI images. The main lesion in the left deep white matter is surrounded by edema, with a mass effect on the ventricle

megakaryocytic or erythrocytic precursors were found in the brain (not shown). However, adenopathy (Fig. 2E) exhibited a predominance of myeloid polymorphic localization and mature elements with megakaryocytes (Fig. 2F-G), and elements of erythrocytic lineage (not shown) were also found. No blastic elements were found in the node (Fig. $2 \mathrm{H}$ ) or other localizations (not shown). The bone marrow (Fig. 2I-J) exhibited a predominance of a myelomonocytic line, but no immature cells. The spleen, lungs, and liver contained mostly myeloid and monocytic elements, without megakaryocytes (not shown). These various elements suggest brain, splenic, liver, lung, and lymph node localization of myelomonocytic leukemia, without any evidence for evolution of the CMML to acute leukemia.

\section{Discussion and conclusion}

We describe the case of a 59 year-old man followed up for 2 years for a CMML who presented with an uncommon presentation of fatal CMML with cerebral and multiorgan involvement. To the best of our knowledge, such diffuse cerebral parenchymal involvement of CMML has not been previously reported in the literature. This case highlights the importance of evoking the diagnosis of cerebral involvement by CMML in the presence of neurologic alterations and multiple MRI brain lesions.

The diagnosis of CMML is made according to the criteria of World Health Organization (WHO) 2016 classification [4] and requires both the presence of persistent monocytosis $\geq 1 \times 10^{9} / \mathrm{L}$ and monocytes accounting for $\geq 10 \%$ of the white blood cell differential count. Two forms of CMML are described according to the WBC count, the "proliferative" type with WBC $\geq 13 \times 10^{9} / \mathrm{L}$ and the "dysplastic" type with $\mathrm{WBC}<13 \times 10^{9} / \mathrm{L}$.

The bone marrow blast percentage, which is of prognostic importance, is used to define three groups of CMML: CMML-0, a category for cases with $<2 \%$ blasts in peripheral blood and $<5 \%$ in bone marrow; CMML-1 for cases with $2-4 \%$ blasts in peripheral blood and/or 5-9\% in the bone marrow and CMML-2 for cases with $5-19 \%$ blasts in peripheral blood and/or 10-19\% in bone marrow.

Extramedullary involvement by CMML is uncommon. Other cases of brain involvement in the context of CMML have been reported but are substantially different from ours.

Meningeal infiltration was described by Rogulj et al. in which the patient presented with headache, and MRI showed signs of leukoencephalopathy and cortical atrophy. The bone marrow showed CMML in an accelerated phase. The patient was treated by chemotherapy with cytarabine and methotrexate for cerebral diffusion, which relieved the symptoms [5]. In a case of CML in blast crisis, multiple small enhancing nodules in the brain, with myeloid blasts in the central nervous system and diffuse leptomeningeal enhancement during the blast crisis, were described by Lai et al. [6]. In our case, signs of leukemic evolution of the CMML were sought and found to be absent, and the MRI imaging characteristics were completely different. In one case of CMML, chronic subdural fluid collection was reported by Bernat et al., but the patient presented with a unique lesion that could be drained by craniotomy. The authors also discussed medical treatment and radiation therapy [7]. A brain pseudotumoral inflammatory lesion was described by Joubert et al. in 2013 [1]. These cases can all be explained by systemic inflammatory and/or autoimmune manifestations, such as those that occur in connective tissue disease or systemic vasculitis, $[8,9]$ which may be associated with myeloid malignancies.

Our case underlines the necessity of ruling out differential diagnoses of cerebral pseudoinflammatory tumors, as well as leukemic evolution of CMML and CML. The absence of Philadelphia chromosome and of hyperleukocytosis at diagnosis ruled out the diagnoses of CML, atypical CML (aCML), and chronic neutrophilic leukemia. 

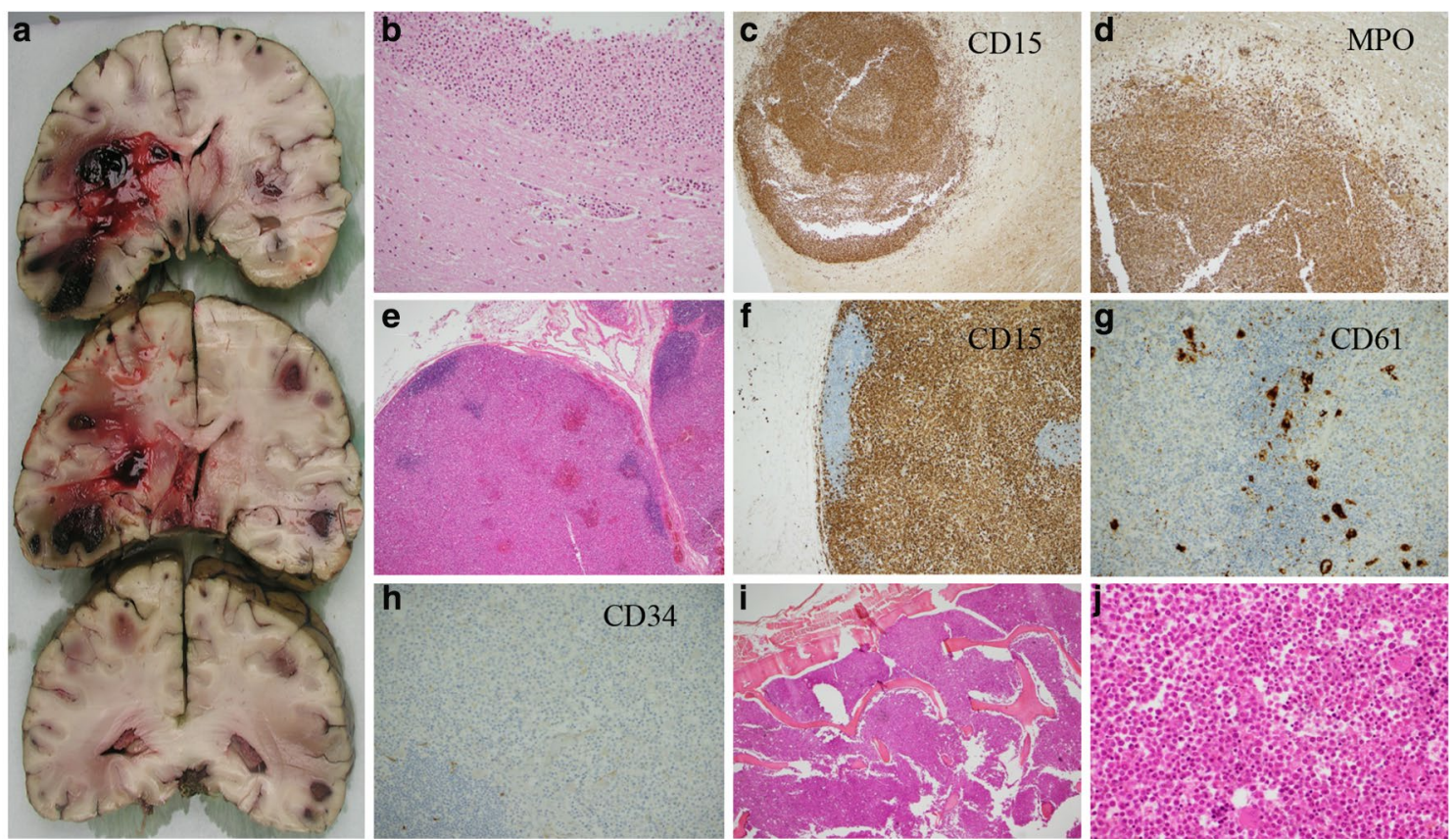

Fig. 2 A Macroscopic sections of the brain showing the hemorrhagic aspect of the lesions. B Microscopic section of the brain with standard hematoxylin and eosin (H\&E) coloration; magnification 10x. C Microscopic section of the brain with anti-CD15 staining by immunohistochemistry (myelomonocytic marker); magnification 2x. D Microscopic section of the brain with anti-MPO staining by immunohistochemistry;

magnification $4 \times$. E Microscopic section of a lymph node with standard H\&E coloration; magnification $2 \times$. F Microscopic section of a lymph node with anti-CD15 staining by immunohistochemistry; magnification 4x. G Microscopic section of a lymph node with anti-CD61 staining (platelet marker) by immunohistochemistry; magnification 10x. H Microscopic section of a lymph node with anti-CD34 staining by immunohistochemistry; magnification 10x. I Bone-marrow section; magnification 2x.J Bone-marrow section; magnification 20x

There have been no reports of such brain lesions in the differential diagnosis of MDS. Furthermore, lymphadenopathy infiltration with ectopic hematopoiesis has never been described in the context of CMML.

In accordance with the EHA recommendations [10], the treatment of CMML also depends on the risk group.

For low-risk patients, monitoring alone may be sufficient, or in the case of anemia, transfusions support can be provided.

For patients who are not eligible for allogenic transplantation, several therapies exist. Hydroxyurea can be used for proliferative CMML0-1 without significant cytopenia, whereas hypomethylating agents are used in CMML1-2 with significant cytopenia. Allogeneic bone marrow transplantation remains the treatment of choice for younger patients with higher-risk disease, and intensive chemotherapy may be considered as a bridge to transplant in aggressive presentations.

The fatal outcome of our patient raises the question of the potential benefit of early specific treatment, such as demethylating agents or intensive chemotherapy.

This unusual description of a rapidly evolving CMML associated with the multiple-hemorrhage MRI presentation may help clinical decision-making in the future.

\section{Abbreviations}

AML: Acute myeloid leukemia; ANA: Antinuclear antibodies; CMML: Chronic myelomonocytic leukemia; CML: Chronic myeloid leukemia; CMV: Cytomegalovirus; CT-Scan: Computed tomography scan; EBV: Epstein-Barr virus; EHA: European Hematology Association; HBV: Hepatitis B virus; HCV: Hepatitis C virus; HIV: Human immunodeficiency viruses; MDS: Myelodysplastic syndrome; MPD: Myeloproliferative disease; MPO: Myeloperoxidase; MRI: Magnetic resonance imaging; NGS: Next-generation sequencing; PET scan: Positron emission tomography scan; R-IPSS: Revised international prognostic scoring system; VAF: Variant allelic fraction; WBC: White blood cells.

\section{Acknowledgements \\ Not applicable.}

\section{Authors' contributions}

$\mathrm{CH}, \mathrm{JC}, \mathrm{OH}$, and $\mathrm{EG}$ analyzed and interpreted the patient data concerning the hematological disease and neurological problems. CD and JPC interpreted and reflected on the diagnosis of the lesions found on MRI. CR and FA performed the autopsy and interpreted the histological sections. All authors read and approved the final manuscript.

\section{Funding}

Not applicable.

\section{Availability of data and materials} Not applicable. 


\section{Declarations}

Ethics approval and consent to participate

Not applicable.

\section{Consent to publication}

Written informed consent was obtained from the patient's next of kin for publication of this case report and any accompanying images. A copy of the written consent is available for review by the Editor-in-Chief of this journal.

\section{Competing interests}

The authors have no competing interests to declare.

\section{Author details}

${ }^{1}$ Department of Hematology, Tours Hospital, Tours, France. ${ }^{2}$ Department of Anatomopathology, Tours Hospital, Tours, France. ${ }^{3}$ Department of Radiology, Tours Hospital, Tours, France. ${ }^{4}$ Department of Neurosurgery, Tours Hospital, Tours, France. ${ }^{5}$ Department of Biology, Tours Hospital, Tours, France.

Received: 23 December 2020 Accepted: 7 June 2021

Published online: 25 July 2021

\section{References}

1. Joubert B, Desestret $\mathrm{V}$, Rheims S. Brain pseudo-tumoral inflammatory lesion associated with chronic myelomonocytic leukemia. J Neurooncol. 2013:113:149-50.

2. Laborde RR, et al. SETBP1 mutations in 415 patients with primary myelofibrosis or chronic myelomonocytic leukemia: independent prognostic impact in CMML. Leukemia. 2013. https://doi.org/10.1038/leu.2013.97.
3. Patnaik MM, Tefferi A. Chronic myelomonocytic leukemia: 2018 update on diagnosis, risk stratification and management HHS public access. Am J Hematol. 2018:93:824-40.

4. Arber DA, et al. Review Series. The updated WHO classification of hematological malignancies. The 2016 revision to the World Health Organization classification of myeloid neoplasms and acute leukemia. Blood. 2016. https://doi.org/10.1182/blood-2016-03-643544.

5. Rogulj IM. Meningeal infiltration of chronic myelomonocytic. Leukemia. 2014. https://doi.org/10.4172/2329-6917.1000147.

6. Lai SW, Huang TC, Chen JH, Wu YY, Chang PY. Dasatinib as the salvage therapy for chronic myeloid leukemia with blast crisis and central nervous system involvement: a case report. Oncol Lett. 2015;9:1957-61.

7. Bernat $\mathrm{AL}$, et al. Chronic subdural collection overlying an intra-axial hemorrhagic lesion in chronic myelomonocytic leukemia: special report and review of the literature. Expert Rev Neurother. 2018;18:371-7.

8. Kristinsson SY, et al. Chronic immune stimulation might act as a trigger for the development of acute myeloid leukemia or myelodysplastic syndromes. J Clin Oncol. 2011;29:2897-903.

9. Kipfer B, et al. Increased cardiovascular comorbidities in patients with myelodysplastic syndromes and chronic myelomonocytic leukemia presenting with systemic inflammatory and autoimmune manifestations. Semin Hematol. 2018;55:242-7.

10. Itzykson R, Fenaux P. Diagnosis and treatment of chronic myelomonocytic leukemia in adults. Blood Res. 2021;56:5-16.

\section{Publisher's Note}

Springer Nature remains neutral with regard to jurisdictional claims in published maps and institutional affiliations.
Ready to submit your research? Choose BMC and benefit from:

- fast, convenient online submission

- thorough peer review by experienced researchers in your field

- rapid publication on acceptance

- support for research data, including large and complex data types

- gold Open Access which fosters wider collaboration and increased citations

- maximum visibility for your research: over $100 \mathrm{M}$ website views per year

At BMC, research is always in progress.

Learn more biomedcentral.com/submissions 